\title{
Cloning, Expression, and Chromosomal Localization to 11p12-13 of a Human LIM/HOMEOBOX Gene, hLim-1
}

\author{
WEI-FENG DONG, ${ }^{1}$ HENRY H.Q. HENG,${ }^{2}$ ROBERT LOWSKY, ${ }^{1}$ YI XU, ${ }^{1}$ JOHN F. DECOTEAU, ${ }^{1}$ \\ XIAO-MEI SHI, ${ }^{2}$ LAP-CHEE TSUI, ${ }^{2}$ and MARK D. MINDEN ${ }^{1}$
}

\begin{abstract}
We have identified a putative transcription factor, designated hLim-1, from human fetal brain using degenerate polymerase chain reaction (PCR) and cDNA library screening. The deduced open reading frame, derived from sequencing a 3.0-kb hLim-1 cDNA, encodes a protein of 384 amino acids with two cysteine-rich LIM domains and one homeobox (HOX) DNA-binding domain. The nucleotide sequence of hLim-1 cDNA is 87\% identical to mouse Lim-1 and the predicted amino acid sequence is greater than $97 \%$ conserved. Expression patterns of hLim-1 were evaluated by Northern analysis and reverse transcription (RT)-PCR coupled with Southern blotting. HLim-1 expression was observed in human brain, thymus, and tonsillar tissue. Expression of hLim-1 was also observed in $58 \%$ of acute myelogenous leukemia (AML) cell lines and in four of five primary samples from patients with chronic myeloid leukemia (CML) in myeloid blast transformation. The gene encoding hLim-1 was mapped using fluorescence in situ hybridization (FISH) to human chromosome 11p12-13. The expression pattern and structural characteristics of the hLim-1 gene suggest that it encodes a transcriptional regulatory protein involved in the control of differentiation and development of neural and lymphoid cells. Its expression in CML in blast crisis suggests that it may be involved with progression in this disease; a prospective study is required to confirm this.
\end{abstract}

\section{INTRODUCTION}

G ENES CONTAINING HOMEODOMAINS play an important role in the growth and differentiation of the developing embryo and the adult animal. The genes encoding homeodomain proteins may be broadly classed as either clustered or dispersed. This latter group of homeotic genes can be further divided based upon the presence of certain functional motifs in addition to the DNA-binding homeodomain; one such motif is the LIM domain, first recognized in the Lin 11 gene of Caenorhabditis elegans (Freyd et al., 1990), isl-1 of mammalian cells (Karlsson et al., 1990), and mec-3 of C. elegans (Way and Chalfie, 1988). The LIM motif consists of cysteine-rich regions capable of complexing zinc and forming finger-like structures. These zinc finger motifs have been shown to be involved in protein-protein interactions; to date, there is no convincing evidence of DNAbinding activity.

Members of the LIM-hox family of genes that have been identified include Lin 11, isl-1, mec-3, xLim-1 (Taira et al.,
1992), mLim-1 (Barnes et al., 1994), rLH2 (Xu et al., 1993), hLH2 (Wu et al., 1996), and mLim-3 (Seidel et al., 1994). Lin 11 and mec 3 are important in the determination of cell fate in mechanosensory neurons and vulval cells, respectively. $\mathrm{mLH} 2$ was first identified in developing B lymphocytes. The gene is expressed in early precursors and is absent from the mature progeny, suggesting a role in the differentiation of the cells $(\mathrm{Xu}$ et al., 1993). LH2 is also expressed in pituitary cells and appears to have a role in the regulation of expression of pituitary glycoprotein hormone $\alpha$-subunit gene (Roberson et al., 1994). mLIM3 is expressed in the neuroepithelium of embryos and in adult life it is expressed in the anterior and intermediate lobes of the pituitary. $x$ Lim- 1 is predominantly expressed during embryogenesis in the gastrula stage and in the adult is expressed in the brain (Taira et al., 1992). The murine homologue, mLim1 , is predominantly expressed in the brain and kidney in the embryo and adult (Barnes et al., 1994).

Using degenerate oligonucleotides, we identified the expression of mLim- 1 in mouse fetal brain, liver and spleen. We

\footnotetext{
${ }^{1}$ Ontario Cancer Institute, Princess Margaret Hospital, Departments of Medicine, Medical Biophysics, and Institute of Medical Sciences, University of Toronto, Canada, M5G 2M9.

${ }^{2}$ Department of Molecular and Medical Genetics, The Hospital For Sick Children, University of Toronto, Canada M5G 2 M9.
} 
cloned mouse Lim-1 and used this as a probe to isolate the human homologue. The gene is expressed in brain, tonsil, and thymus of adult humans. In addition, we found aberrant expression of hLim-1 in a variety of human primary leukemias and human leukemic cell lines. Human Lim-1 was mapped by fluorescent in situ hybridization to chromosome band 11p12-13.

\section{MATERIALS AND METHODS}

\section{Cell lines and patient samples}

Peripheral blood or bone marrow was obtained from normal individuals and from patients with leukemia following informed consent. Mononuclear cells were isolated by Ficoll-Hypaque centrifugation. $\mathrm{T}$ lymphocytes were removed from peripheral blood samples by E-rosetting with sheep red blood cells followed by a second Ficoll-Hypaque centrifugation (Minden $e t$ al., 1979). Cells were either used immediately to prepare RNA and DNA or were stored in liquid nitrogen in $\alpha$-minimal essential medium (MEM) containing 10\% dimethylsulfoxide (DMSO) and 50\% fetal calf serum (FCS). The cell lines evaluated are listed in Table 1.

To prepare a $\mathrm{CD} 34^{+}$enriched cell population, mononuclear bone marrow cells from a normal individual were depleted of adherent cells by plastic adherence. The cells were then incubated on ice with fluoroisothiocyanate (FITC)-conjugated antiCD34 monoclonal antibody (Serotec, Quebec) for $1 \mathrm{hr}$. Five times $10^{5} \mathrm{CD}_{3}{ }^{+}$cells were then separated using fluorescenceactivated cell sorting (FACStar, Becton Dickinson, San Jose, CA).

\section{RNA isolation}

Total RNA was extracted from peripheral blood, bone marrow, and the cell lines and from several different fetal mouse tissues by a guanidinium thiocyanate-based method (Chirgwin et al., 1979).

\section{cDNA synthesis}

Total RNA $(1 \mu \mathrm{g})$ was added to a $20-\mu$ l solution containing $40 \mathrm{~m} M$ Tris- $\mathrm{HCl} \mathrm{pH} 8.3,50 \mathrm{~m} M \mathrm{KCl}, 5 \mathrm{~m} M$ dithiothreitol (DTT), $2 \mathrm{mM} \mathrm{MgCl} 2,10 \mathrm{pM}$ of random hexamer (Pharmacia), $2 \mu M$ of each deoxyribonucleotide triphosphate (dNTP), $1 \mu l$ (40 units) of RNasin ribonuclease inhibitor (Promega Corp., Madison, WI) and $1 \mu \mathrm{l}$ (100 units) of Moloney murine leukemia virus reverse transcriptase (RT) (GIBCO-BRL, Canada). This mixture was incubated at $37^{\circ} \mathrm{C}$ for $45 \mathrm{~min}$.

Table 1. Expression of hLim-1 in Normal Cells and Malignant Cell Lines

\begin{tabular}{|c|c|c|}
\hline & Lineage & hLim-1 \\
\hline \multicolumn{3}{|l|}{ Normal tissue } \\
\hline PB mononuclear cells & Mature $\mathrm{T}$ and $\mathrm{B}$ leukocytes & - \\
\hline BM cells & Developing hematopoietic tissue & - \\
\hline CD341 cells & $\mathrm{BM}$ progenitor cells & - \\
\hline Brain & Nervous system & +++ \\
\hline Placenta & Fetal tissue & - \\
\hline Tonsil & Lymphoid tissue & ++ \\
\hline Testis & Reproductive tissue & - \\
\hline Thymus & Precursor T-lymphoid & $+t$ \\
\hline \multicolumn{3}{|l|}{ Cell line } \\
\hline OCI/AML-1 & Acute myelogenous leukemia & ++ \\
\hline OCI/AML-2 & Acute myelogenous leukemia & ++ \\
\hline OCVAML-3 & Acute myelogenous leukemia & +++ \\
\hline OCI/AML-4 & Acute myelogenous leukemia & +++ \\
\hline OCI/AML-5 & Acute myelogenous leukemia & - \\
\hline OCI/AML-6 & Acute myelogenous leukemia & - \\
\hline KG-1 & Acute myelogenous leukemia & - \\
\hline NB-4 & Acute promyelocytic leukemia & - \\
\hline U937 & Acute monocytic leukemia & - \\
\hline HEL & Erythroleukemia & - \\
\hline TF-1 & Erythroleukemia & + \\
\hline MO7E & Megakaryoblastic leukemia & - \\
\hline K562 & Chronic myelogenous leukemia myeloid blast crisis & +++ \\
\hline ALL-Sil & T-cell lymphoblastic leukemia & - \\
\hline KOPKT-1 & T-cell lymphoblastic leukemia & + \\
\hline MKB-1 & T-cell lymphoblastic leukemia & - \\
\hline MOLT-16 & T-cell lymphoblastic leukemia & - \\
\hline HUT-78 & Cutaneous T-cell lymphoma & - \\
\hline OCI/Ly-13.1 & T-cell lymphoma at presentation & +++ \\
\hline OCI/Ly-13.2 & T-cell lymphoma at relapse & +++ \\
\hline $\mathrm{OCI} / \mathrm{Ly}-8$ & B-cell lymphoma & - \\
\hline A-172 & Glioblastoma & + \\
\hline HeLa & Epitheliod carcinoma & - \\
\hline
\end{tabular}

$(-)$ Not detectable; $(+)$ weakly positive; $(+++)$ strongly positive. 


\section{Generation of mouse Lim-1 (mlim-1) probe by PCR cloning}

Total cell RNA extracted from fetal mouse brain, liver, spleen, and thymus was reverse-transcribed into single-strand cDNA as described above. cDNA was then mixed with two degenerate primers; $5^{\prime}$-(C/A)G(A/G)GGACC(T/A)(C/A)G(A/G)ACNACNAT-3' (primer A, sense strand corresponding to RGPRTTI and 5'-(A/G)TT(T/C)TGAAACCA(G/C)ACC(T/C)G$3^{\prime}$ (primer $\mathrm{B}$, antisense strand corresponding to QVWFQN); the location of the primers is shown in Fig. 1A. The final reaction volume was $100 \mu \mathrm{l}$, containing $0.2 \mathrm{mM}$ of each dNTP, $2.5 \mathrm{mM}$ $\mathrm{MgCl}_{2}, 50 \mathrm{mM} \mathrm{KCl}, 10 \mathrm{mM}$ Tris- $\mathrm{HCl} \mathrm{pH} \mathrm{8.3}$, and 2.5 units of Taq polymerase. The target domain was amplified using the following conditions: two cycles at $94^{\circ} \mathrm{C}$ for $1 \mathrm{~min}, 37^{\circ} \mathrm{C}$ for $2 \mathrm{~min}$, and $72^{\circ} \mathrm{C}$ for $1 \mathrm{~min}$, followed by 30 cycles at $94^{\circ} \mathrm{C}$ for $1 \mathrm{~min}, 50^{\circ} \mathrm{C}$ for $1 \mathrm{~min}$, and $72^{\circ} \mathrm{C}$ for $1 \mathrm{~min}$. A final 10 -min extension at $72^{\circ} \mathrm{C}$ was added after the last cycle. The amplified 0.16-kb band was purified from an agarose gel and was cloned into a TA cloning vector using blue/white selection (TA cloning kit, Invitrogene). White colonies were picked and sequenced using dideoxy sequencing. Sequence analysis and comparison were done using the University of Wisconsin Genetics Computer Group programs. The clone containing the polymerase chain reaction (PCR) fragment displaying the highest degree of DNA sequence homology with Xlim-1 was purified and the fragment was labeled to a high specific activity with $[\alpha-$ $\left.{ }^{32} \mathrm{P}\right] \mathrm{dCTP}$ by random priming with hexanucleotides.

\section{Human cDNA library screening}

Plaques $\left(10^{6}\right)$ of a human fetal brain cDNA library in the $E c o$ RI site of $\lambda$ ZapII (Stratagene) were screened using the 0.16kb PCR fragment of mLim-1 as a random-primed probe. Overnight hybridization was performed at $60^{\circ} \mathrm{C}$ in hybridization solution containing $4 \times \mathrm{SET}, 0.1 \%$ sodium pyrophosphate, $0.2 \% \mathrm{NaDodSO}_{4}$, and $500 \mu \mathrm{g} / \mathrm{ml}$ of heparin. The final washing condition was $0.2 \times \mathrm{SSC}, 0.1 \% \mathrm{NaDodSO}_{4}$ at $60^{\circ} \mathrm{C}$ for 20 min. In vivo excision of the positive clones was performed as per the instructions from the manufacturer (Stratagene).

\section{DNA sequencing of hLim-1 cDNA clone}

DNA sequencing of the hLim-1 clone was carried out using the Sanger dideoxy method with Sequenase, Version 2.0 (U.S. Biochemicals). The universal M13 primers and four oligonucleotides derived from sequences obtained from various subclones of the 3.0-kb cDNA were used as primers. DNA sequences and their corresponding amino acid sequences were analyzed using the University of Wisconsin Genetics Computer Group program. The sequence was deposited in GenBank (accession \#U14755).

\section{Expression of hLim-1 detected by Northern blotting and by RT-PCR coupled with Southern blotting}

For Northern blotting, a commercially available human multitissue blot (Stratagene) was used as a source of RNA and hybridized with the full-length $\mathrm{hLim}-1 \mathrm{cDNA}$ as a random-primed probe or with a random-labeled internal probe to $\beta$-actin. Autoradiography was performed at $-70^{\circ} \mathrm{C}$ for $12-48 \mathrm{hr}$ using Kodak XAR film.
For detection of hLim-1 by reverse transcription (RT)-PCR coupled with Southern blotting, $5 \mu$ l of cDNA obtained from RNA prepared from a variety of human tissue sources was mixed in $100 \mu$ l of solution containing $10 \mathrm{~m} M$ Tris- $\mathrm{HCl} \mathrm{pH} 8.3,50 \mathrm{mM}$ $\mathrm{KCl}, 1.5 \mathrm{mM} \mathrm{MgCl}, 0.4 \mu M$ of each dNTP, $10 \%$ dimethylsulfoxide (DMSO) and 2.5 units of Taq polymerase. The hLim-1specific oligonucleotide primers hLM715F (5'-AACAAGCAGCTCTCCACT-3', sense) and hLM1107R (5'-GACCTGAATGACGCGCAT- $3^{\prime}$, antisense) were added at a final concentration of $50 \mathrm{pM}$. These primers correspond to the regions spanning nucleotides 715-732 (hLM715F) and 1,093-1,110 (hLM1110R) of hLim-1 cDNA. Reaction mixtures were ampli-

A

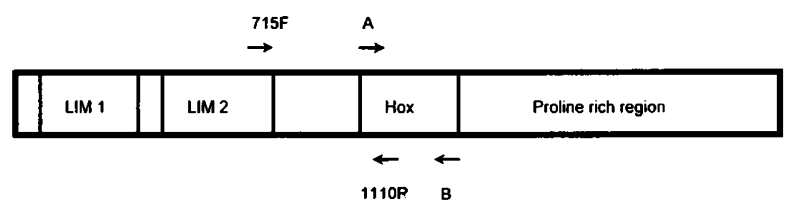

B

GAATTCCCGGCGCTTTCCTCGCAACCCGAGCTCGGCGAGTCGTCGTCTTCTTCTTCTCCG 60 TTTTTATTTATTTATTTCCGTTCCCGCCGCCGTTCTCGCTGACCTTCACTCCTCCGCGGG 120 CTCTGAGCAGAAGGGTCGCATTCTCTCCCGCCTGAGACTTCTTTTCCTCGCCCCGGGAGC 181 TCAGGCGGCGCGCTCCAGCCCGGGGCCCCGGACTCCCCGGCTGCACACTTCACTGAGACG 240 CCCCCAGGCCCGATCAGCCTCGTTCTCCACCCTACTTTGATTTCCTGGTGCGAGTTTTGG 300 CTTGCACGGCCGAGTGTGTGTCCTCTTTTTGGAGAGACTGGGGAGCTCGTGCCGATTGTC 360 TTCAGGAGTCATCCCCTGGGCTCTACTTTGCCCCTCTCTCTCTCTGGGCCTCATCAGACC 420 AAACCAAAGACCATGGTTCACTGTGCCGGCTGCAAAAGGCCCATCCTGGACCGCTTTCTC 480

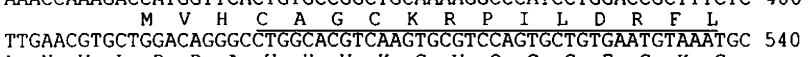

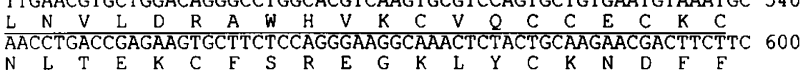

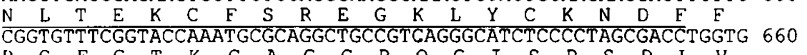
$\begin{array}{llllllllllllllllllll}\text { R } & \text { C } & \text { F } & \text { G } & \text { T } & \text { K } & \text { C } & \text { A } & \text { G } & \text { C } & \text { R } & \text { Q } & \text { G } & \text { I } & \text { S } & \text { P } & \text { S } & \text { D } & \text { L } & \text { V } \\ \text { CGGAGAGCGCGGAGGAAAGTGTTTCACCTGAACTGCTTCACCTGCATGATGTGTAACAAG } & 720\end{array}$

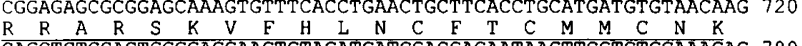
$\begin{array}{lllllllllllllll}R & R & A & R & S & K & V & F & H & L & N & & & \end{array}$

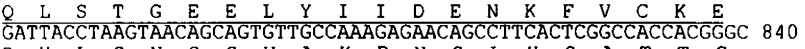

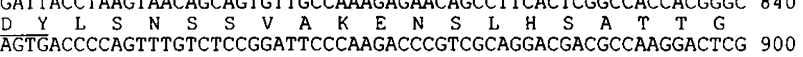

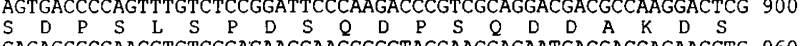
$\begin{array}{llllllllll} & \end{array}$ $\begin{array}{llllllllllllllllll}\text { GGCGCCAAGCGGCGGGGACCCGGCACCACCATCAAAGCCAAGCAGCTGGAGACGCTGAAG } & 1020\end{array}$

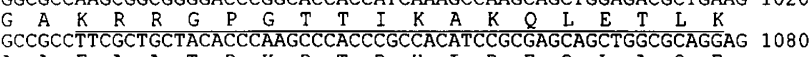

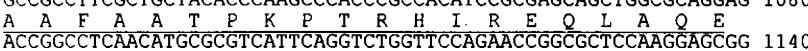

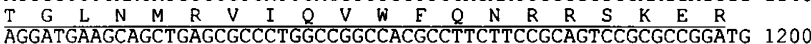

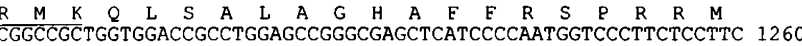
$\begin{array}{llllllllllllllllllll}R & P & L & V & D & R & L & E & P & G & E & L & I & P & N & G & P & F & S & E\end{array}$ TACGGAGATTACCAGAGCGAGTACTACGGGCCCGGGGGCAACTACGACTTCTTCCCGCAA 1320 $\begin{array}{llllllllllllllllllll}\text { Y } & \text { G } & \text { D } & \text { Y } & \text { Q } & \text { S } & \text { E } & \text { Y } & \text { Y } & \text { G } & \text { P } & \text { G } & \text { G } & \text { N } & \text { Y } & \text { D } & \text { F } & \text { F } & \text { P } & \text { Q } \\ \text { GGCCCCCCGTCCTTCGCAGGCCCAGACACCAGTTGGACCTACCCTTCGTGCCGTCATCTGGG } & 1380\end{array}$ GGCCCCCGTCCTCGCAGGCCCAGACACCAGTGGACCTACCCTTCGTGCCGTCATCTGGG 1380

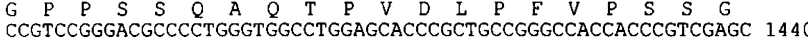
$\begin{array}{llllllllllllllllllllll}P & S & G & T & P & L & G & G & L & E & H & P & L & P & G & H & H & P & S & S\end{array}$ GAGGCGCAGCGGTTTACCGACATCCTGGCGCACCCACCCGGGGACTCGCCCAGCCCCGAG 1500 $\begin{array}{llllllllllllllllllll}E & A & Q & R & F & T & D & I & L & A & H & P & P & G & D & S & P & S & P & E\end{array}$ CCCAGCCTGCCCGGGCCTCTGCACTCCATGTCGGCCGAGGTCTTCGGACCCAGCCCGCCC 1560 TTCTCGTCGCTGTCGGTCAACGGTGGGGCGAGCTACGGAAACCACCTGTCCCACCCCCCC 1620

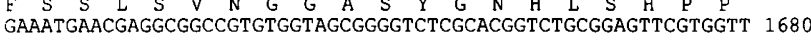
E M N E A A V W *

GTACAGAAATGAACCTTTATTTAAGAAAATAG

FIG. 1. A. Schematic representation of Lim-1 showing the sites of the degenerate primers to the Hox domain (primer A forward, primer B reverse). For the amino acids encoded by these primers see Materials and Methods. The sites of the LIM domains, homeodomain, and proline-rich region are shown. $715 \mathrm{~F}$ and $1110 \mathrm{R}$ are the primers used for RT-PCR expression studies. B. Nucleotide sequence and deduced amino acid sequence of hLim-1 cDNA. The tandem copies of the LIM motifs followed by the homeobox domain are underlined. The insertion site of the domain encoding the alternative transcript is indicated by the bolded arrow. 
fied by PCR in standard fashion. Parallel experiments, which included primers specific for the $\beta$-actin gene, were amplified in similar fashion and served as controls. PCR products were transferred onto a Hybond- $\mathrm{N}^{+}$nylon membrane (Amersham, Oakville, ON) using the procedure described by Southern (1975) and hybridized, where appropriate, with either the full-length hLim- 1 cDNA as a random-primed probe or with a random-labeled internal probe to the $\beta$-actin PCR product. Autoradiography was performed at $-70^{\circ} \mathrm{C}$ for $12 \mathrm{hr}$ using Kodak XAR film.

Samples were considered positive for hLim- 1 expression if a band of appropriate size $(\sim 0.4 \mathrm{~kb})$ was observed by hybridization with the full-length hLim-1 cDNA. Samples were considered to be negative if RT-PCR amplification of $5 \mu \mathrm{l}$ of the cDNA reaction mixture did not yield a band by hybridization whereas a human $\beta$-actin band of appropriate size $(\sim 0.5 \mathrm{~kb})$ was visible after gel electrophoresis and ethidium bromide staining.

\section{Chromosome localization by fluorescence in situ hybridization}

Plaques $\left(10^{6}\right)$ from a human genomic library made from a leukemic sample were screened with a hLim-1 cDNA probe. A hLim-1-specific phage clone containing a 16-kb insert was identified and confirmed by hybridization with several hLim-1 oligonucleotides.

Lymphocytes isolated from human cord blood were cultured in $\alpha$-MEM containing $10 \%$ FCS and phytohemagglutinin (PHA) at $37^{\circ} \mathrm{C}$ for $68-72 \mathrm{hr}$. Lymphocyte cultures were then treated with bromodeoxyuridine (BrdU) $(0.18 \mathrm{mg} / \mathrm{ml}$; Sigma, St. Louis, MO) to synchronize the cell population. The synchronized cells were washed three times with serum-free medium to release the block and recultured for $6 \mathrm{hr}$ in $\alpha$-MEM containing thymidine ( $2.5 \mu \mathrm{g} / \mathrm{ml}$; Sigma). Cells were harvested, and metaphase spreads were prepared using standard procedures. The hLim-1-containing phage clone was labeled with biotinylated dATP (BioNick, GIBCO-BRL) at $15^{\circ} \mathrm{C}$ for $1 \mathrm{hr}$. Fluorescence in situ hybridization (FISH) was performed as previously described (Heng et al., 1992). Briefly, slides were baked at $55^{\circ} \mathrm{C}$ for $1 \mathrm{hr}$, and following RNase A treatment, the DNA was denatured in $70 \%$ formamide in $2 \times \mathrm{SSC}$ for $1 \mathrm{~min}$ at $70^{\circ} \mathrm{C}$ and then dehydrated with ethanol. The biotinylated hLim-1 genomic probe was denatured at $75^{\circ} \mathrm{C}$ for $5 \mathrm{~min}$ in a hybridization mix of $50 \%$ formamide, $2 \times \mathrm{SSC}$, and $10 \%$ dextran sulfate. After overnight hybridization, the slides were washed and the signals were revealed by fluorescein-labeled avidin (Oncor Inc., Canada) Chromosomes were identified by staining with 4',6-diamidino-2-phenylindole (DAPI). Assignment of FISH mapping data with chromosomal bands was achieved by superimposing FISH signals with DAPIbanded chromosomes (Heng and Tsui, 1993).

\section{RESULTS}

\section{Isolation and sequence of mLim-1 gene}

At the time of initiation of our studies, the murine homolog of XLim-1 had not been deduced. To screen a human cDNA library, we generated a mLim-1 probe using XLim-1 as a template. RNA extracted from fetal mouse brain, liver, and spleen was reverse transcribed and the cDNA was used for amplification by RT-PCR. Using the degenerate primers A and B, corre- sponding to the RGPRTTI and QVWFQN amino acid sequences in the homeodomain of Xlim-1, respectively, a predicted product of $0.16-\mathrm{kb}$ was amplified reproducibly (Fig. 1A). The purified band was cloned into a plasmid vector and 20 clones sequenced. Analysis revealed that two classes of sequences were obtained. One sequence class, isolated from fetal brain and spleen, displayed $82 \%$ homology with the Xlim-1 homeobox domain, and was therefore named mLim-1. The other sequence class, isolated from all three fetal tissues, showed homology with a human $\alpha$-fetoprotein gene enhancer binding protein gene, $\alpha \mathrm{F}$ $\mathrm{PEB}$, which encodes a zinc finger homeobox protein. Because our primary interest is in identifying members of the LIM-Hox family, this result was not pursued further.

\section{Cloning, sequencing, and structure of hLim-1 cDNA}

The mLim-1 fragment was used as a probe to screen a human fetal brain cDNA library. A clone containing a $3.0-\mathrm{kb}$ insert was identified and 1.712-kb of the $5^{\prime}$-end was sequenced (Fig. 1B). The sequence, termed hLim-1, was deposited in GenBank (accession no. U14755) and represents the human homolog of Xlim1. Figure 1 shows the nucleotide and deduced amino acid sequences of this 1.712-kb cDNA. Overall, the nucleotide sequence of the coding region displays $87 \%$ homology with $\mathrm{mLim}-1,85 \%$ homology with chicken Lim-1 (cLim-1), and 79\% homology with Xlim-1. The $5^{\prime}$ untranslated region of hLim- 1 is $432 \mathrm{bp}$ in length. It is of note that the first $220 \mathrm{bp}$ of the $5^{\prime}$ untranslated region is $70 \%$ identical with the mouse $5^{\prime}$ untranslated region, whereas there is no homology between these two sequences over the remainder of the $5^{\prime}$ untranslated region. This conservation of sequence suggests that there may be a regulatory function of the 5 ' untranslated sequences. The translated region extends from nucleotides 433 to 1,643 . A comparison of the nucleic acid sequences of mLim-1 and hLim-1 was $87 \%$ similar; however, at the amino acid level, the sequence was $97 \%$ identical (Fig. 2). Like other Lim-hox genes, the Lim domain is ahead of the homeobox domain. The $3^{\prime}$ untranslated region of $\mathrm{hLim}-1$ is approximately $1.3-\mathrm{kb}$ in length; this has not been sequenced.

\section{Gene expression}

Expression of hLim-1 was $\sim$ valuated first by Northern blotting using a commercially available human multitissue blot and RNA extracted from two human leukemia cell lines. Expression of hLim-1 was not detected in normal tissue; however, a 4.0-kb band corresponding to the full-length transcript was detected in RNA of the K562 cell line, a line derived from the leukemic cells of a patient with chronic myeloid leukemia (CML) in myeloid blast transformation (Fig. 3).

The ability to detect hLim-1 expression was enhanced when evaluated by RT-PCR coupled with Southern blotting of RNA from normal tissues. RT-PCR products were observed in samples from human brain, tonsil, and thymus, but not peripheral blood mononuclear cells, normal bone marrow, or $\mathrm{CD} 34^{+}$bone marrow cells, colon, testis, ovary, or placenta. In RNA from brain and tonsil, there were two bands of $405 \mathrm{bp}$ and $498 \mathrm{bp}$, whereas in thymus only the smaller band was present (Fig. 4).

To identify the nature of the 405- and 498-bp bands, both were cloned and sequenced. The 405 -bp band has a sequence identical to the cDNA isolated from the brain cDNA library. The 498-bp fragment was identical to the 405-bp band except 


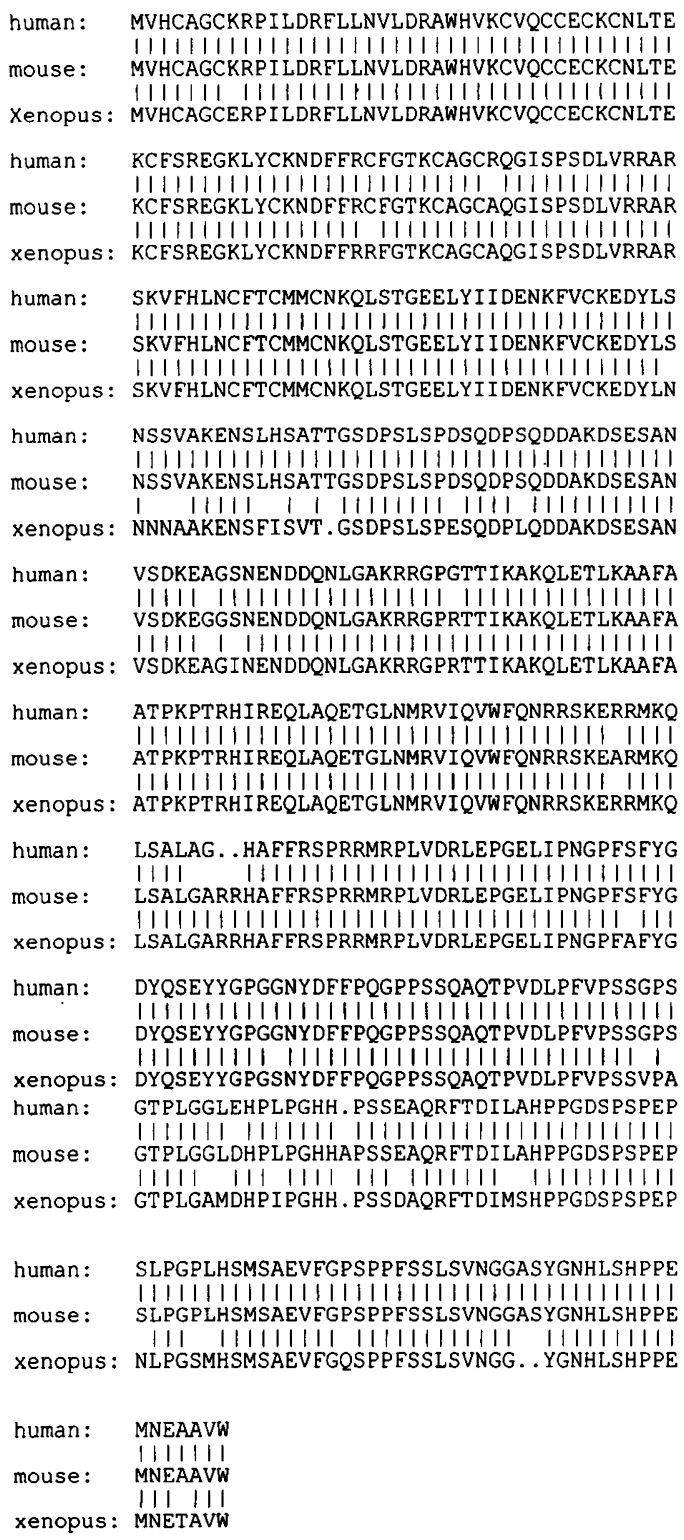

FIG. 2. Amino acid sequence alignment of XLim-1, mLim1 , and hLim-1. Vertical bars indicate identical residues.

for a 93-bp insert beginning at nucleotide 829; the insert maintains the reading frame (Fig. 5). To determine the genomic structure responsible for these two forms, we performed PCR on normal DNA using the same two primers. This resulted in the amplification of a 498-bp piece. Inspection of this sequence revealed potential splice donor sites of GGGT beginning at position 828 of the full-length cDNA and a potential splice acceptor of AGCC 93 bp downstream. Because the PCR primers used in the RT-PCR experiments are potentially in the same exon, we confirmed that the larger 498-bp RT-PCR product was derived from RNA and not genomic DNA by treating samples with RNase or DNase. Pretreatment of the samples with RNase eliminated both bands. Pretreatment of the samples with DNase did not alter the result, thus indicating that the RT-PCR product is derived from RNA and not DNA.
40

8
1 , a cell line derived from an acute T-cell leukemia, which ex-

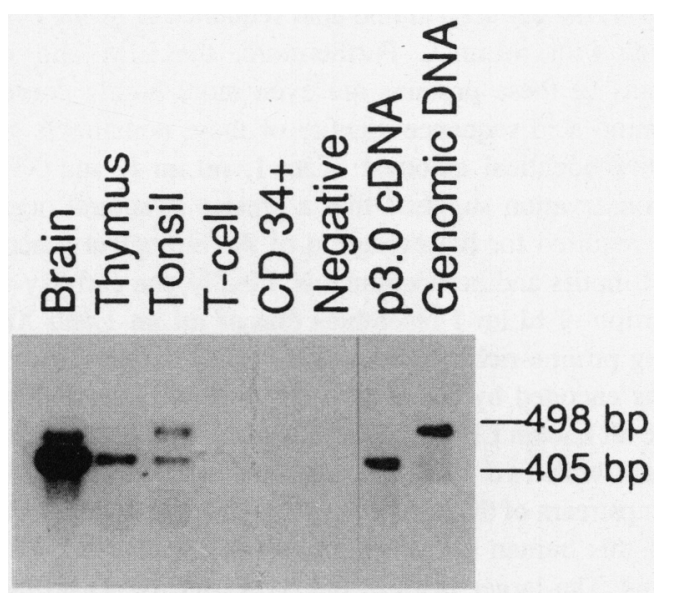

FIG. 4. RT-PCR coupled with Southern blotting to detect hLim-1 expression. cDNA prepared from the tissue and cell populations indicated were amplified as outlined in Materials and Methods. Specific amplification of hLim-1 was performed using the hLM715F and hLM1110R oligoprimers. A plasmid containing hLim-1 cDNA and normal human genomic DNA were used as positive control samples. The lane indicated as negative contained no template DNA. 


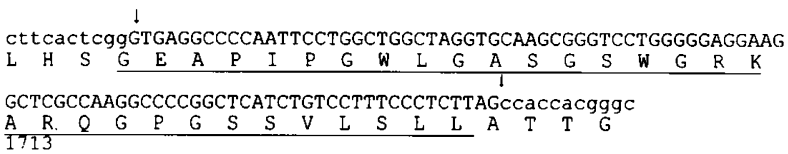

FIG. 5. Sequence analysis of the large isoform of hLim-1. RTPCR using CDNA from tonsil was performed, and the large isoform was sequenced after isolation from an agarose gel. The nucleotide sequence and its deduced amino acid sequence are shown. The uppercase letters represent the 93-bp insert; the deduced amino acid sequence is shown below and is underlined. The vertical arrows show the boundaries of the additional sequences.

pressed only the smaller isoform. In contrast, none of the 13 samples from patients with AML and only 1 of 9 chronic-phase CML patient samples expressed hLim-1 RNA (Table 2). Of note, however, was the finding of hLim-1 expression in four of five samples obtained from patients with CML in myeloid blast transformation.

\section{Chromosome mapping of hLim-1 by FISH}

FISH, using the 16-kb hLim-1 containing phage DNA clone as a labeled probe, revealed exclusive labeling to chromosome 11 (Fig. 6A,B). A total of 15 metaphase spreads were scored, of which 10 were photographed. Signals were assigned to 11p12-13 (Fig. 6C).

\section{DISCUSSION}

In this study, we report the cloning, expression, and chromosomal localization of hLim-1, the proposed human homolog of $\mathrm{mLim}-1$ and XLim-1. The evidence that hLim-1 is, in fact, the homolog of the above-mentioned genes is convincing. The cDNA nucleotide sequence of the coding region of hLim- 1 is $87 \%$ and $79 \%$ identical with mLim-1 and XLim-1, respectively. Moreover, the deduced amino acid sequence of hLim-1 is $97 \%$ identical with mLim-1. Furthermore, the LIM and homeodomains of these proteins are even more highly conserved. The amino acid sequence identity of these domains is greater than $99 \%$ identical amongst hLim-1, mLim-1, and XLim-1. This conservation suggests that a precise structural organization is required for the execution of the biological function(s) of LIM motifs and homeodomains. Finally, the carboxy-terminal portion of hLim-1 resembles that of $\mathrm{mLim}-1$ and XLim-1 in being proline-rich, whereas, this region is glutamine-rich in proteins encoded by many other LIM-class homeobox genes.

Like all known LIM-class homeobox genes, hLim- 1 encodes a protein with two tandemly repeated cysteine-rich LIM domains upstream of the homeodomain. The unique structural feature of this human homolog, however, is that it encodes two isoforms. The larger isoform has an additional $93 \mathrm{bp}$ inserted between the LIM domains and the homeodomain. These two different forms arise as a result of alternative splicing. The additional sequences in the RNA results in the in-frame addition of 31 amino acids in the region between the distal LIM domain and the homeobox domain. Whether this insert has any functional significance is not known.

Barnes et al. used RNase protection to evaluate the expression of mLim-1 in adult tissues. They found high levels of ex- pression in cerebellum, medulla, and kidney and very low levels in cerebrum. They did not test thymus or tonsil, although spleen was negative by this method for mLim-1 expression. We used the more sensitive RT-PCR method to detect hLim-1 expression in adult human tissues. High levels of expression were found in brain, thymus, and tonsil; the other tested tissues were negative. We did not test expression in human kidney. It is of note that hLim-1 is expressed in a hierarchical manner in the $\mathrm{T}$-cell lineage because cells from the thymus were positive, whereas peripheral blood mononuclear cells, composed primarily of mature $\mathrm{T}$ cells, were negative. This pattern of restricted expression is in keeping with other LIM-class homeobox genes thus far described. In the adult mouse, the restricted pattern of mLim-1 expression suggests a role in the maintenance of differentiated renal tissue and in the maintenance of differentiated cell populations within the central nervous system (CNS) (Barnes et al, 1994). Likewise, the expression pattern of LH-2, another mammalian LIM/homeobox gene, suggests that this protein may serve as a transcription factor involved in the differentiation of distinct B- and T-cell subpopulations (Xu et al., 1993).

The inability to detect hLim-1 expression in normal tissue by Northern blotting, but its detection in selected tissue by RT-

TABLE 2. EXPRESSION OF HLIM-1 in Primary Leukemia Samples

\begin{tabular}{llc}
\hline Diagnosis & Clinical Status & hLim-1 \\
\hline AML-M1 & Presentation & - \\
AML-M2 & Presentation & - \\
AML-M2 & Presentation & - \\
AML-M2 & Presentation & - \\
AML-M2 & Relapse & - \\
AML-M4 & Presentation & - \\
AML-M4 & Presentation & - \\
AML-M4 & Presentation & - \\
AML-M4 & Relapse & - \\
AML-M4 & Relapse & - \\
AML-M5 & Presentation & - \\
AML-M7 & Presentation & - \\
AML-M7 & Presentation & - \\
CML-CP & Presentation & - \\
CML-CP & Presentation & - \\
CML-CP & Presentation & - \\
CML-CP & Presentation & - \\
CML-CP & Presentation & + \\
CML-CP & Presentation & - \\
CML-CP & Presentation & - \\
CML-CP & Presentation & - \\
CML-CP & Presentation & - \\
CML-BP & Presentation & - \\
CML-BP & Presentation & ++ \\
CML-BP & Presentation & ++ \\
CML-BP & Presentation & + \\
CML-BP & Presentation & + \\
\hline
\end{tabular}

AML is classified using the FAB (French-American-British) classification.

CML is classified using the NCI criteria: CP denotes first chronic phase and BC denotes blast crisis. The symbol represents no detectable hLim-1 expression, + represents weak positive, and +++ represents strongly positive. 


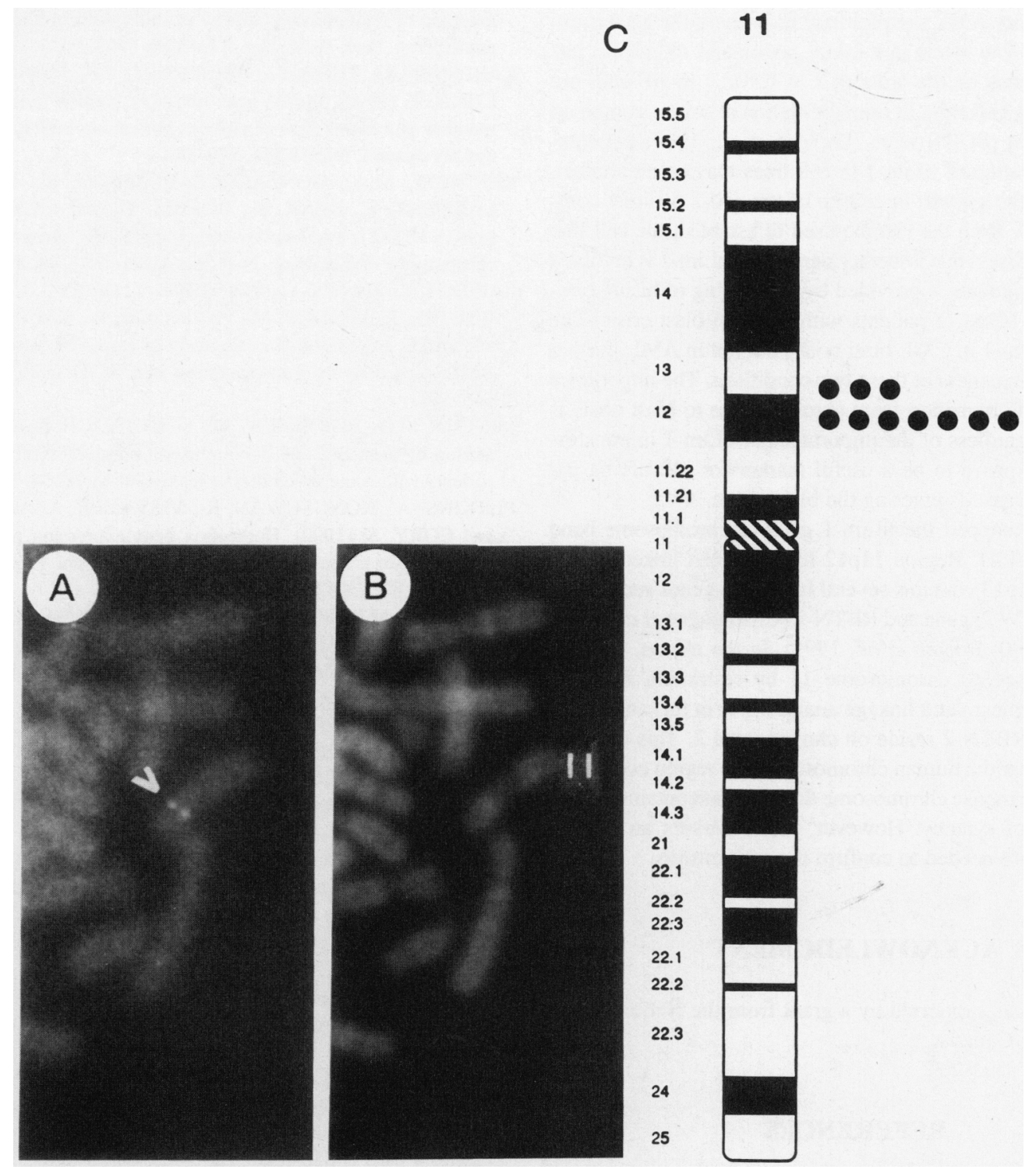

FIG. 6. A. hLIM-1 gene mapped to human chromosome band 11p12-13 using FISH biotinated hLim-1 genomic phage DNA. The biotinylated probe was hybridized to metaphasic chromosomes of normal human lymphocytes and detected with fluoresceinlabeled avidin. Fluorescent signals are indicated by arrows. B. Visualization of chromosome banding with staining with 4,6-diamidino-2-phenylindole (DAPI). C. Ideogram of human chromosome 11 showing the location of hLIM-1 gene. Each dot represents the location of a double-fluorescent signal on chromosome 11.

PCR indicates that hLim-1 is expressed at relatively low levels. In contrast, some malignant cells overexpress hLim-1, as shown by our detection using Northern blotting of hLim-1 transcripts in the K562 cell line. The aberrant expression of proteins containing LIM and/or Hox domains has been previously shown to be implicated in the genesis of leukemias. The RBTN2 gene, which encodes a LIM-domain protein, was originally identified by its involvement in a recurrent chromosomal translocation in T-cell acute lymphoblastic leukemia (ALL) and subsequently its overexpression has been shown to have transforming activity in transgenic mice (Fisch et al., 1992). Hox genes have also been implicated in the development of leukemia as a result of chromosomal translocations and activation by retroviral insertion (Perkins et al., 1990; Kennedy et al., 1991).
The finding of hLim- 1 overexpression in K562, coupled with the observation of hLim-1 expression in lymphoid tissue and precursor $\mathrm{T}$ cells, led to a more extensive evaluation of its expression profile in a variety of hemato-lymphoid tumor cell lines and in primary leukemia samples. Overall, hLim-1 expression in human leukemia and lymphoma cell lines was variable, but with a preponderance in AML cell lines. We believe that the finding of $\mathrm{hLim}-1$ expression in AML cell lines is significant, because a relatively pure population of $\mathrm{CD}_{3} 4^{+}$normal bone marrow cells, the postulated normal counterpart of leukemia cells of myeloid origin, did not express hLim-1. Interestingly, hLim-1 expression was not detected in the evaluation of primary AML samples; this is similar to our findings of $\mathrm{hLH} 2$, another Lim/Hox gene (Wu et al., 1996). The inability to detect 
hLim-1 in primary AML samples may be because the gene is expressed at very low levels in a minor population of cells; it has been estimated that on the order of 1 in $10^{4}$ to 1 in $10^{5}$ cells are able to establish leukemia in immune-deficient severe combined immunodeficient (SCID) mice (Lapidot et al., 1994). Alternatively, the activation of $\mathrm{hLim}-1$ in cell lines may be an artefact, resulting from the growth in culture of the cells. A direct comparison of RNA from the sample used to establish the cell line is required to address this issue. Evidence that hLim-1 is involved in leukemia in patients is provided by the finding of hLim-1 expression in the blasts of patients with CML in blast crisis. The presence of hLim-1 in CML blast crisis, but not in AML, further confirms the uniqueness of these two conditions. The importance of hLim-1 in the transition from chronic phase to blast crisis is not known. Regardless of the importance of hLim-1 in transformation, it may prove to be a useful marker for identifying patients whose disease is entering the blast phase.

Finally, we mapped the hLim-1 gene to chromosome band 11p12-13 by FISH. Region 11p12 has not been linked to any diseases, but 11 p13 contains several important genes such as the Wilm's tumor (WT) gene and RBTN-2 (Champagne et al., 1989; Rose et al., 1990; Boehm et al., 1991). In the mouse, mLim-1 has been mapped to chromosome 11 by restriction fragment length polymorphism and linkage analysis, yet in this animal the WT gene and RBTN-2 reside on chromosome 2 . This observation suggests that the human chromosome $11 \mathrm{p}$ region containing hLim- 1 and the mouse chromosome domain that contains mLim1 are regions of synteny. However, more markers around the hLim-1 locus are needed to confirm the relationship.

\section{ACKNOWLEDGMENT}

This work was supported by a grant from the National Cancer Institute of Canada.

\section{REFERENCES}

BARNES, J.D., CROSBY, J.L., JONES, C.M., WRIGHT, C.V.E., and HOGAN, B.L.M. (1994). Embryonic expression of Lim-1, the mouse homolog of the Xenopus XLim-1, suggests a role in lateral mesoderm differentiation and neurogenesis. Dev. Biol. 161, 168-178.

BOEHM, T., FORONI, L., KANEKOO, Y., PERUTZ, M.F., and RABBITTS, T.H. (1991). The rhombotin family of cysteine rich LIM domain oncogenes: distinct members involved in T-cell translocations to human chromosomes 11 p15 and 11p13. Proc. Natl. Acad. Sci. USA 88, 4367-4371.

CHAMPAGNE, E., TAKIHARA, Y., SAGMAN, U., DE SOUSA, J., BURROW, S., LEWIS, W.H., MAK, T.W., and MINDEN, M.D. (1989). The T-cell receptor delta chain locus is disrupted in the T-ALL associated $t(11 ; 14)(p 13 ; q 11)$ translocation. Blood 73, 1672-1676.

CHIRGWIN, J.M., PRXBYLA, A.E., MCDONALD, R.J., and RUTTER, W.J. (1979). Isolation of biochemically active ribonucleic acid from sources enriched in ribonuclease. Biochemistry 18, 5294-5299.

FISCH, P., BOEHM, T., LAVENIR, I., LARSON, T., ARNO, J., FORSTER, A., and RABBITTS, T.H. (1992). T-cell acute lymphoblastic lymphoma induced in transgenic mice by the RBTN1 and RBTN2 LIM-domain genes. Oncogene 7, 2389-2397.

FREYD, G., KIM, S.K., and HORVITZ, H.R. (1990). Novel cysteine rich motif and homeodomain in the product of the Caenorhabditis elegans cell lineage gene lin-11. Nature 344, 876-879.

HENG, H.H.Q., SQUIRE, J., and TSUI, L. (1992). High-resolution mapping of mammalian genes by in situ hybridization to free chromatin. Proc. Natl. Acad. Sci. (USA) 89, 9509-9513.

KARLSSON, O., THOR, S., NORBERG, T., OHLSSON, H., and EDLUND, T. (1990). Insulin gene enhancer binding protein Isl-1 is a member of a novel class of proteins containing both a homeo and a cys-his domain. Nature 344, 879-882.

KENNEDY, M.A., GONZALEZ-SARMIENTO, R., KEES, U.R., LAMPERT, F., DEAR, N., BOEHM, T., and RABBITTS, T.H. (1991). HOX11, a homeobox-containing T-cell oncogene on human chromosome 10q24. Proc. Natl. Acad. Sci. USA 88, 8900-8904.

LAPIDOT, T., SIRARD, C., VORMOOR, J., HOANG, T., CACERESCORTES, J., MINDEN, M., PATERSON, B., CALIGIURI, M.A., and DICK, J.E. (1994). Development of an in vivo assay for human AML stem cells by transplantation into SCID mice. Nature 367, 645-648.

MINDEN, M.D., BUICK, R.N., and MCCULLOCH, E.A. (1979). Separation of blast cell and T-lymphocyte progenitors in the blood of patients with acute myeloblastic leukemia. Blood 54, 186-195.

PERKINS, A., KONGSUWAN, K., VISVADER, J., ADAMS, J.M., and CORY, S. (1990). Homeobox gene expression plus autocrine growth factor production elicits myeloid leukemia. Proc. Natl. Acad. Sci. USA 87, 8398-8402.

ROBERSON, M.S., SCHODERBEK, W.E., TREMML, G., and MAURER, R. (1994). Activation of the glycoprotein hormone $\alpha$ subunit promoter by a LIM-homeodomain transcription factor. Mol. Cell. Biol. 14, 2985-2993.

ROSE, E.A., GLASER, T., JONES, C., SMITH, C.L., LEWIS, W.H., CALL, K.M., MINDEN, M., CHAMPAGNE, E., BONETTA, L., YEGER, H., and HOUSMAN, D.E. (1990). Complete physical map of the WAGR region of $11 \mathrm{p} 13$ localizes a candidate Wilm's tumor gene. Cell 90, 495-508.

SEIDEL, H.M., BARALE, J.C., MARCINKIEWICZ, M., MATTEI, M.B., DAY, R., and CHRETIEN, M. (1994). The mouse homeoprotein mLIM-3 is expressed early in cells derived from the neuroepithelium and persists in adult pituitary. DNA Cell Biol. 13, 1163-1180.

SOUTHERN, E.M. (1975). Detection of specific sequences among DNA fragments separated by gel electrophoresis. J. Mol. Biol. 98, 503-517.

TAIRA, M., JAMRICH, M., GOOD, P.J., and DAWID, I.B. (1992). The LIM domain containing homeo box gen Xlim-1 expressed specifically in the organizer region of Xenopus gastrula embryos. Genes \& Dev. 6, 356-366.

WAY, J.C., and CHALFIE, M. (1988). Mec-3, a homeobox containing gene that specifies differentiation of the touch receptor neurons of C. elegans. Cell 54, 5-16.

WU, H., HENG, H.H.Q., SIDEROVSKI, D.P., DONG, W., OKUNO, Y., SHI, X., TSUI, L., and MINDEN, M.D. (1996). Identification of a human LIM-Hox gene, hLH-2, aberrantly expressed in chronic myelogenous leukemia and located on 9q33-34.1. Oncogene 12, 1205-1212.

XU, Y., BALDASSARE, M., FISHER, P., RATHBUN, G., OLTZ, E.M., YANCOPOULOS, G.D., JESSELL, T.M., and ALT, F.W. (1993). LH2: a LIM/homeodomain gene expressed in developing lymphocytes and neural cells. Proc. Natl. Acad. Sci. USA 90, 227-231.

Address reprint requests to: Dr. Mark D. Minden

Department of Medicine, Medical Biophysics, and Institute of Medical Science Princess Margaret Hospital 610 University Avenue

Toronto, Ontario

M5G 2 M9 Canada

Received for publication August 31, 1996; accepted October 22, 1996. 